\title{
Aerosol particles in the Mexican East Pacific Part I: processing and vertical redistribution by clouds
}

\author{
D. Baumgardner ${ }^{1}$, G. B. Raga ${ }^{1}$, J. C. Jimenez ${ }^{1}$, and K. Bower ${ }^{2}$ \\ ${ }^{1}$ Universidad Nacional Autónoma de México, Mexico City, Mexico \\ ${ }^{2}$ Atmospheric Science Group, University of Manchester, P.O. Box 88, Sackville Street, Manchester, M60 1QD, UK
}

Received: 23 September 2004 - Published in Atmos. Chem. Phys. Discuss.: 29 November 2004

Revised: 15 March 2005 - Accepted: 21 October 2005 - Published: 16 November 2005

\begin{abstract}
Airborne measurements of aerosol particle size distributions were made in the Mexican Intertropical Convergence Zone. The volume concentrations of submicron and super micron particles at cloud base were compared with those in near-cloud regions over a range of altitudes. Of 78 near-cloud regions analyzed, $68 \%$ and $45 \%$ had enhanced volumes of submicron particles and supermicron particles, respectively. In addition, 35\% of these regions had supermicron particles removed, presumably by precipitation. In $61 \%$ of the cases the enhancement in volume occurred over the size range from 0.1 to $50 \mu \mathrm{m}$ whereas only submicron volumes were enhanced in $35 \%$ of the cases. In regions near clouds that were formed in air of maritime origin the frequency of volume enhancement decreased with increasing altitude and was twice as frequent on the dissipating side of clouds compared to the growing side. No such differences were found in the regions near clouds formed in air originating from the land. The frequency and average magnitude of volume enhancement are in qualitative and quantitative agreement with previous observational and theoretical studies that relate enhancements in particle mass to the uptake by cloud droplets of $\mathrm{SO}_{2}$ accompanied by additional growth by droplet coalescence.
\end{abstract}

\section{Introduction}

Aerosol particles (AP) have a dominant role in the evolution and optical properties of clouds. The fundamental process by which a cloud droplet forms on an AP, i.e. a cloud condensation nucleus $(\mathrm{CCN})$, has been described theoretically and validated with observations as long as the composition of the particle is known (e.g. Twomey, 1991; Raga and Jonas, 1993a, b). On the other hand, the fate of AP after process-

Correspondence to: D. Baumgardner

(darrel@servidor.unam.mx) ing by clouds, i.e. changes in size, concentration and composition, is less well understood. Clouds remove AP from the boundary layer and redistribute them through a variety of dynamical and microphysical mechanisms, e.g. entrainment, mixing and precipitation (Flossmann, 1998). It is generally accepted that some fraction of the AP incorporated into cloud particles will eventually appear again as AP but in a chemically or physically altered form. For example, aircraft measurements have found that AP sizes increase near clouds in regions of high relative humidity (Baumgardner and Clarke, 1998) and other studies (Saxena et al., 1970; DeFelice and Cheng, 1998; Kaneyasu et al., 2001) found that condensation nuclei $(\mathrm{CN})$ concentrations are often higher in the outflow from evaporating clouds than in the environment further away. The AP mass will change as a result of particle sulfate and $\mathrm{SO}_{2}$ scavenging (Hegg and Hobbs, 1981, 1982; Flossmann et al., 1985, 1987; Flossmann and Pruppaccher, 1988; O'Dowd et al., 2000).

There have been a number of observational studies of AP interactions with clouds (e.g., Hegg and Hobbs, 1981, 1983; O'Dowd et al., 2000), but very few in the Pacific Intertropical Convergence Zone (ITCZ) and none in the Mexican East Pacific ITCZ. This region is unique as a result of the variation in AP sources, i.e. when the wind direction is westerly the $\mathrm{AP}$ are of maritime origin and $\mathrm{CN}$ concentrations are less than $500 \mathrm{~cm}^{-3}$; however, northerly and easterly winds bring continental, anthropogenic AP from Mexico or Central America and the average, $\mathrm{CN}$ concentrations are greater than $1000 \mathrm{~cm}^{-3}$. These differences in AP origin have significant consequences on cloud formation and the fate of the AP when they are processed by clouds. This paper, part one of two parts evaluates airborne measurements of AP and cloud particles in the ITCZ of the Mexican East Pacific and shows evidence for changes in the AP total volume concentration as a result of cloud processing. Part two, using model simulations, will discuss the direct and indirect effects of AP in this region of the tropics. 


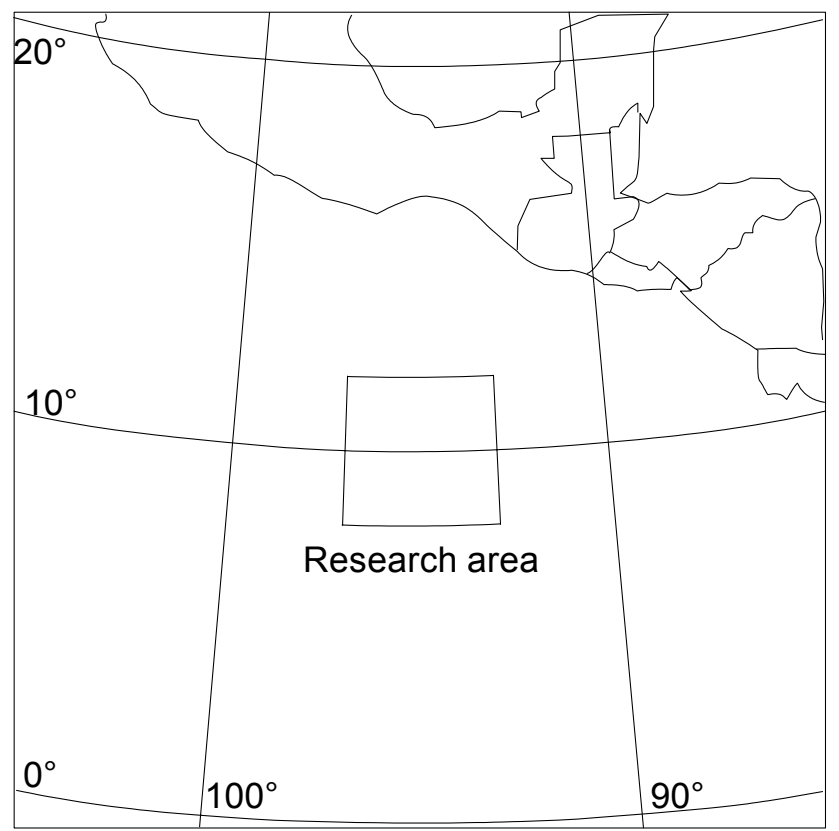

Fig. 1. EPIC-2001 research area during ITCZ flights.

\section{Measurement and analysis methodology}

\subsection{Research area and sampling strategy}

The data used in this study were obtained during flights of the US National Science Foundation C-130 research aircraft during the 2001 East Pacific Investigation of Climate (EPIC) project. The program and scientific objectives are described in the EPIC science and implementation plan (Raymond et al., 2004). Nine of the nineteen flights between 1 September and 16 October 2001 were dedicated to AP and cloud studies. These flights were within the ITCZ region, $8^{\circ}-12^{\circ} \mathrm{N}, 93^{\circ}-$ $97^{\circ} \mathrm{W}$, approximately $800-1000 \mathrm{~km}$ from Mexico and Central America (Fig. 1). Measurements in and around clouds were made at the constant levels of $4200 \mathrm{~m}, 2500 \mathrm{~m}, 1000 \mathrm{~m}$, $300 \mathrm{~m}$ (cloud base) and $30 \mathrm{~m}$ a.s.1. The clouds in the research area consisted of small fields of shallow cumulus and lines of deep convection. The current study focuses on these latter clouds that generally developed along lines from the southwest to northeast. The flight trajectories were across and along the cloud lines at each level. The across-the-line patterns normally sampled in the regions of newer growth and the along-the-line flight legs sampled cells in both developing and decaying stages. In the across-the-line flight tracks the aircraft sampled cloud-free air for at least $20 \mathrm{~km}$ on each side of the cloud.

\subsection{Instrumentation}

The physical properties of AP were derived directly from the composite particle size distribution (PSD) synthesized from the measurements by three optical particle spectrometers that were mounted on the wing pods of the C-130: a Passive Cavity Aerosol Spectrometer (PCASP), and two models of the Forward Scattering Spectrometer Probe (FSSP-300 and FSSP-100) that measure in the size ranges $0.1-3 \mu \mathrm{m}$, $0.3-20 \mu \mathrm{m}$ and $2-50 \mu \mathrm{m}$, respectively. The concentrations in overlapping size ranges were averaged prior to creating the composite. The concentration of $\mathrm{CN}$, larger than approximately $0.05 \mu \mathrm{m}$, was measured with a TSI Model 3760 (Twohy, 1991). All measurements were made at a sample rate of $10 \mathrm{~Hz}$ but averaged into one second intervals for the analysis presented here. The technical specifications of the instruments are listed in Table 1.

The measurement uncertainties associated with the PCASP have been discussed by a number of authors (Kim and Boatman, 1990; Strapp et al., 1992) as have those of the FSSP-100 and FSSP-300 (Baumgardner et al., 1985, 1992; Baumgardner and Spowart, 1990).

The intent of the current study is to evaluate changes in the AP mass that are a result of coalescence or the absorption of gaseous species and not related to uptake of water; hence, the size distributions were adjusted to "dry equivalent" diameters based on the measured relative humidity $(R H)$. A heater on the inlet of the PCASP reduces the $R H$ of the sampled air stream to less than 30\% (Strapp et al., 1992) and so we assume that the PCASP is already measuring dried AP. The FSSP-100 and FSSP-300 measure particles at the ambient $R H$. We had no direct measurements of the chemical composition of the AP so we can't determine the precise relationship between volume change (used here as an indicator of mass change) and $R H$. We recognize that the AP in this region is a mixture of sea salt, ammonium sulfate and organic compounds and their origin might be natural or anthropogenic.

In order to make the most conservative estimate possible of the dry, AP size, we select a particle composition assumed to be the most hygroscopic of those compounds that might be present. Hence, we assume the particles are primarily ammonium sulfate, particles whose water uptake rate is close to that of $\mathrm{NaCl}$ (Tang, 1980). The PSDs measured during each second by the FSSP-300 and FSSP-100 were adjusted by decreasing the size thresholds as a function of the measured $R H$ before synthesizing the composite PSD. The drying factor was taken from the laboratory studies of Tang (1980) that relate the volume change of ammonium sulfate particles to percent $R H$. Figure 2 illustrates the effect of applying this technique to one of the near-cloud volume distributions discussed below. In this example, the volume concentrations in the submicron size regions are 188 and $25 \mu \mathrm{m}^{3} \mathrm{mg}^{-1}$ for the measured and dry equivalent size distributions, respectively. The difference between the measured and dry supermicron regions are 480 and $55 \mu \mathrm{m}^{3} \mathrm{mg}^{-1}$.

For those particles that are not ammonium sulfate or $\mathrm{NaCl}$, the estimated, dry volume will be smaller than their actual dry volume. We illustrate this with two particles, A and 
Table 1. AP and Cloud Particle Instrumentation on the C130 Aircraft.

\begin{tabular}{llll}
\hline Instrument type & Parameter & Range & Accuracy \\
\hline CN counter & Number concentration of aerosol & 0.01 to $>3 \mu \mathrm{m}$ & $\begin{array}{l}\text { Varies with concentration, } \\
\text { TSI Model 3760 }\end{array}$ \\
PCASP & Size spectra of aerosols & 0 to $2 \times 10^{4} \mathrm{~cm}^{-3}$ & $\begin{array}{l}\text { about } 6 \% \text { at } 3300 \mathrm{~cm}^{-3} \\
\end{array}$ \\
& & 30 channels & $\pm 20 \%$ Diameter \\
FSSP-300 & Size spectra of aerosols & 0.3 to $20 \mu \mathrm{m}$ & $\pm 16 \%$ Concentration \\
& & 30 channels & $\pm 16 \%$ Diameter \\
FSSP-100 & Size spectra of aerosols & 2 to $47 \mu \mathrm{m}$ & $\pm 20 \%$ Diameter \\
& and cloud droplets & 40 channels & $\pm 16 \%$ Concentration \\
\hline
\end{tabular}

1 The PCASP, FSSP-100 and FSSP-300 have had their original electronics replace with the signal processing package (SPP) of Droplet Measurement Technologies that improves response time, eliminates dead-time and increases the number of size channels.

$\mathrm{B}$, whose deliquesced diameters are $1 \mu \mathrm{m}$, but the composition of A is ammonium sulfate and particle B is 50\% ammonium sulfate and $50 \%$ some mildly hygroscopic organic compound. For a given $R H$, the amount of water on particle $\mathrm{B}$ will be less than that on particle $\mathrm{A}$, assuming that water molecules are reacting slower with the organo-sulfate mixture. Neglecting the effect of refractive index on the measurement uncertainty, we assume that both of these will be measured as $1 \mu \mathrm{m}$ particles and we will reduce their diameters by the same amount of water removed, based on the measured $R H$. This means that we have erroneously decreased the size of the mixed particle with the result that we are underestimating its true dry size. If the sulfate that was in this mixed particle was a result of cloud processing, then we would lose this information. On the other hand, this is the most stringent test possible, in the absence of knowing the exact composition of the particle, for excluding deliquescence when testing for mass increases that result from cloud processing. We expand upon this argument below.

\subsection{Analysis of cloud processing signatures}

Cloud processing of AP changes their size, concentration or composition. These changes are reflected as differences in the shapes of PSDs, calculated as volume concentrations. More specifically, the PSD can be divided into two regions - the volume concentration of particles with diameter less $<1 \mu \mathrm{m}$ (submicron) and those greater than $1 \mu \mathrm{m}$ (supermicron). The concentrations are computed with respect to the mass rather than volume of air in order to compare the volumes from different altitudes. We assume that the majority of cloud droplets form on CCN that enter through cloud base (Flossmann, 1998). Hence, we use the average submicron and supermicron volume concentrations of AP at $300 \mathrm{~m}$ "farfrom-cloud" as our reference when comparing with volume concentrations near cloud. We use $300 \mathrm{~m}$ as the reference level since this was the average altitude of cloud base. The average "far-from-cloud" PSDs were created from measure-

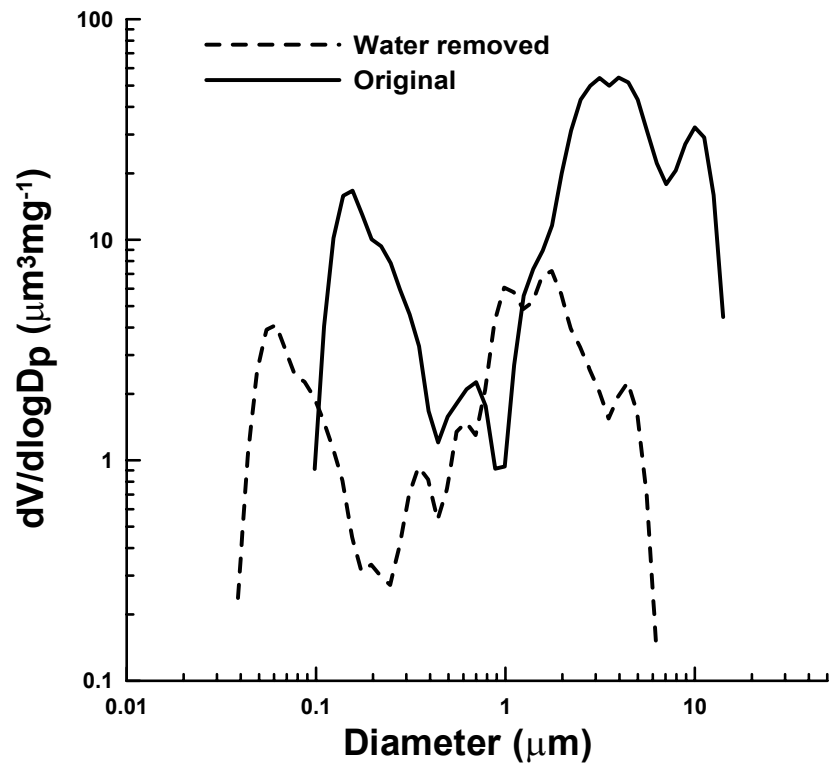

Fig. 2. The two particle distributions of volume concentration as a function of size illustrate the effect of estimating the dry equivalent size from the $R H$, assuming the particles are composed completely of ammonium sulfate.

ments during an entire flight, excluding any region, at all levels, closer than $10 \mathrm{~km}$ to a cloud.

The "near-cloud" regions are defined as those where the equivalent potential temperature, $\Theta_{e}$, differs by more than one degree from the environmental $\Theta_{e}$ at that level, determined from the average vertical profiles made in the farfrom-cloud regions. The time series in Fig. 3 shows two "near-cloud" regions where one side is designated as the "growing" side (69922-69929) and the other the "dissipating" side (70 141-70 181). The cloud edge is determined from the particle concentrations measured by the FSSP-100, whose lower size threshold is approximately $2 \mu \mathrm{m}$. When the concentration exceeds $1 \mathrm{~cm}^{-3}$ the measurements are defined 
Table 2. Characteristics of cloud systems selected for analysis.

\begin{tabular}{cccccccc}
\hline $\begin{array}{c}\text { Flight } \\
\#\end{array}$ & $\begin{array}{c}\text { Date } \\
2001\end{array}$ & Cloud System & $\begin{array}{c}\text { Time Period } \\
\text { UTC }\end{array}$ & Location & Particle Source & $\begin{array}{c}\text { Maximum } \\
\text { CN Conc. cm }\end{array}$ & $\begin{array}{c}\text { Maximum } \\
\text { PCASP Conc. } \mathrm{cm}^{-3}\end{array}$ \\
\hline 7 & $9 / 16$ & 1 & $16: 46-17: 19$ & $12.3^{\circ} \mathrm{N}, 93.7^{\circ} \mathrm{W}$ & Continental & 995 & 212 \\
7 & $9 / 16$ & 2 & $18: 42-20: 12$ & $11.9^{\circ} \mathrm{N}, 95.2^{\circ} \mathrm{W}$ & Continental & 995 & 212 \\
9 & $9 / 20$ & 3 & $18: 16-20: 11$ & $10.5^{\circ} \mathrm{N}, 95.9^{\circ} \mathrm{W}$ & Continental & 923 & 384 \\
9 & $9 / 20$ & 4 & $18: 56-20: 24$ & $8.2^{\circ} \mathrm{N}, 95.8^{\circ} \mathrm{W}$ & Continental & 923 & 384 \\
12 & $9 / 28$ & 5 & $17: 03-18: 12$ & $9.3^{\circ} \mathrm{N}, 93.9^{\circ} \mathrm{W}$ & Marine & 550 & 180 \\
12 & $9 / 28$ & 6 & $19: 14-20: 20$ & $11.9^{\circ} \mathrm{N}, 94.1^{\circ} \mathrm{W}$ & Marine & 550 & 180 \\
13 & $9 / 29$ & 7 & $18: 31-19: 03$ & $11.4^{\circ} \mathrm{N}, 94.6^{\circ} \mathrm{W}$ & Marine & 428 & 54 \\
13 & $9 / 29$ & 8 & $19: 36-20: 22$ & $12.4^{\circ} \mathrm{N}, 949^{\circ} \mathrm{W}$ & Marine & 428 & 54 \\
17 & $10 / 6$ & 9 & $18: 34-19: 49$ & $11.9^{\circ} \mathrm{N}, 93.9^{\circ} \mathrm{W}$ & Continental & 1700 & 522 \\
17 & $10 / 6$ & 10 & $20: 51-21: 36$ & $11.8^{\circ} \mathrm{N}, 94.1^{\circ} \mathrm{W}$ & Continental & 1700 & 522 \\
\hline
\end{tabular}

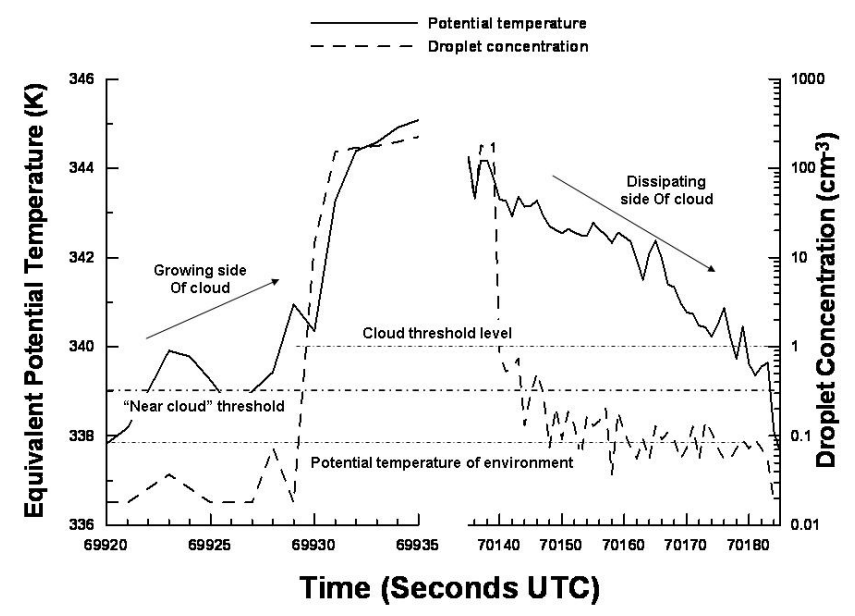

Fig. 3. This time series of equivalent potential temperature (solid line) and droplet concentration (dashed line) is an example of air near cloud boundaries where cloud is defined as the FSSP100 droplet concentration $>1 \mathrm{~cm}^{-3}$. Air that has mixed with cloud is identified by having a potential temperature different than the environment ( $338 \mathrm{~K}$ in this example) by $>1$ degree.

as "in-cloud". This criterion is based on an evaluation of measurements at an altitude of $30 \mathrm{~m}$ where there are no clouds and only supermicron sea salt particles will be measured by the FSSP-100, in the absence of any significant vertical mixing of cloudy air from higher altitudes. These supermicron particles are the first to be activated at low supersaturations during cloud formation, hence an average concentration of $<1 \mathrm{~cm}^{-3}$ sets the lower limit for the cloud droplet concentration when there has been no entrainment and mixing with environmental, droplet-free air.

The growing versus dissipating regions are distinguished by the rate at which the equivalent potential temperature changes as cloud edge is approached. In the example shown in Fig. 3, $\Theta_{e}$ on the growing side increases from the environmental value of 338 to the in-cloud value of 344 in ten sec- onds of flight (approximately $1000 \mathrm{~m}$ ) compared to the other side of the cloud, designated the dissipating region, where the same magnitude change in $\Theta_{e}$ occurs over $4000 \mathrm{~m}$, or approximately $40 \mathrm{~s}$. In the following evaluation, growing regions are those whose $\Theta_{e}$ values reach the environmental $\Theta_{e}$, $\pm 1^{\circ}$ in less than $1000 \mathrm{~m}$. All others are classified as dissipating. The determination of growing versus dissipating is made for each near-cloud region, independent of what was found for the regions above or below for the same cloud.

An additional criterion is imposed in the selection of nearcloud regions for analysis: the region must be at least a kilometer in width, i.e. $10 \mathrm{~s}$ of flight, to ensure a statistically representative measurement of the supermicron droplets. The FSSP-100 samples $30 \mathrm{~cm}^{3}$ of air each second at $100 \mathrm{~ms}^{-1}$. The average, environmental concentration of supermicron particles is approximately $0.1 \mathrm{~cm}^{-1}$. Hence, the FSSP will sample $300 \mathrm{~cm}^{3}$ in ten seconds and will detect approximately 30 particles with an estimated standard deviation of \pm 5 , or $17 \%$.

In the following analysis, we make the following assumptions: 1) that the AP in the near-cloud regions are a mixture of cloud processed and ambient air from the same altitude, 2) that the AP in cloud, either as cloud droplet nuclei or interstitial particles, have originated at cloud base and do not change significantly in total number concentration while in cloud, and 3) that our technique for removing water mass as a function of ambient $R H$ provides the conservative estimate of the dry diameter, i.e. the particle size changes will be a result of increased mass by cloud processing, not by deliquescence. These assumptions allow us to estimate the magnitude of dry AP volume change as a result of cloud processing.

The sub and super micron volume concentration is used here as a metric because we are assuming that the primary change in particle characteristics, as a result of in-cloud processes, will be the increase of AP mass as a result of the uptake of precursor gases by cloud droplets, scavenging of interstitial particles or droplet coalescence. 


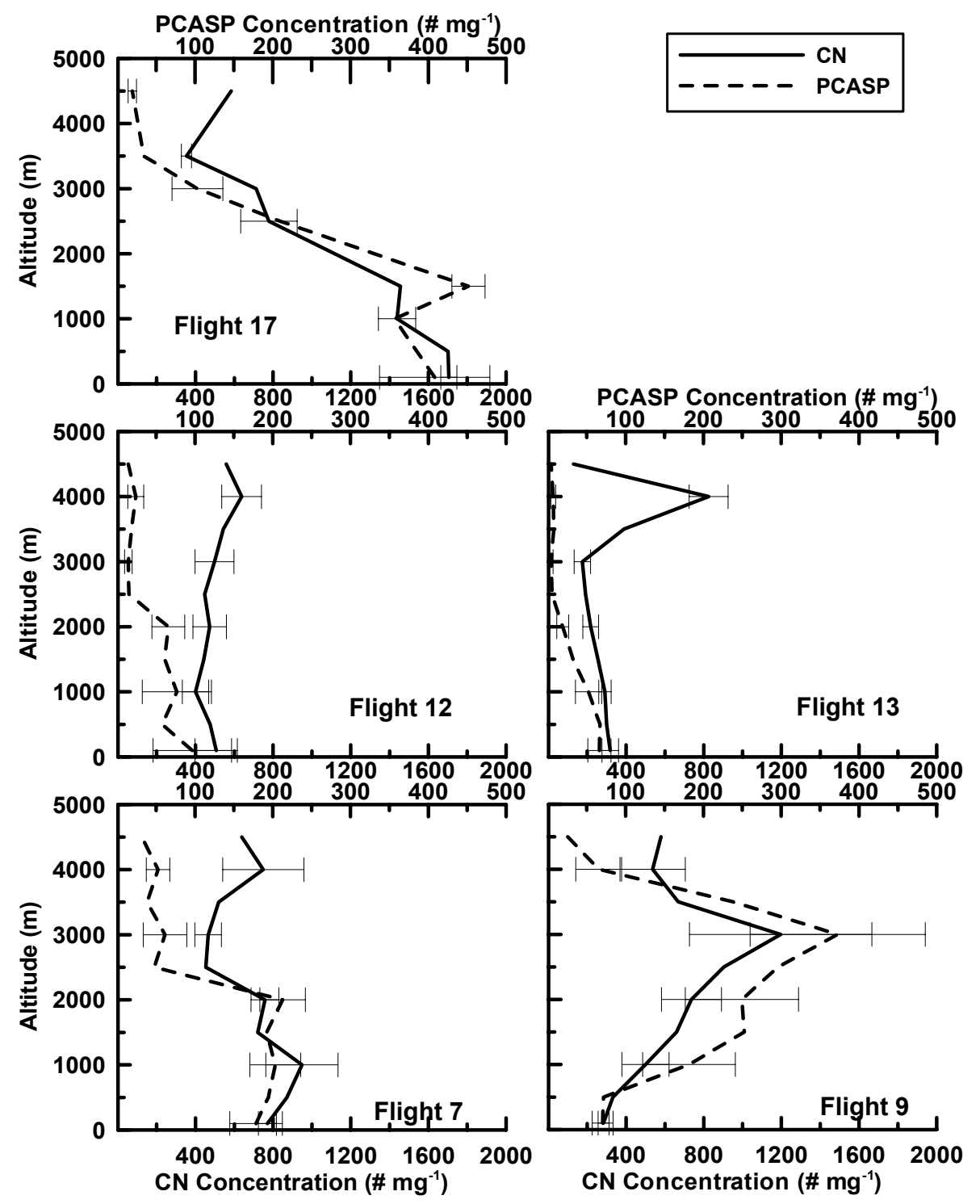

Fig. 4. The origin of the air masses during the five research days is indicated here by the far-from-cloud vertical distributions of $\mathrm{CN}$ (solid) and PCASP (dashed) concentrations. An average CN concentration less than $500 \mathrm{~cm}^{-3}$ is indicative of marine air, while larger concentrations are evidence of continental air masses.

The cloud processing of AP is evaluated by deriving the difference between the particle volume concentration in nearcloud regions, $V_{n c}$, and the cloud-free concentration, $V_{300}$, at $300 \mathrm{~m}$, taking into account mixing between the air detrained from the cloud and the environment. This residual volume, $V_{r}$ is calculated from the measurements:

$V_{r}=V_{n c}-f V_{f c}-(1-f) V_{300}$

where $V_{f c}$ is the volume concentration in the far-from-cloud environment at the same altitude as $V_{n c}$ and $f V_{f c}$ represents how much of the far cloud air has mixed with the detrained air. If no cloud processing has occurred, we assume that $V_{n c}$ will simply be some mixture of AP that came from cloud base and AP from the far-from-cloud environment, at the level of entrainment. This assumes only lateral mixing and that all sizes scale linearly. The factor, $f$, is estimated from the measured concentrations of $\mathrm{CN}$ at $300 \mathrm{~m}, \mathrm{CN}_{300}$, but farfrom-cloud, and the near and far-from-cloud $\mathrm{CN}$ concentrations $\mathrm{CN}_{n c}$ and $\mathrm{CN}_{f c}$ :

$$
\begin{aligned}
& f=\left(\mathrm{CN}_{n c}-\mathrm{CN}_{300}\right) /\left(\mathrm{CN}_{f c}-\mathrm{CN}_{300}\right) \quad Z>300 \mathrm{~m} \\
& f=\left(\mathrm{CN}_{n c}-\mathrm{CN}_{300}\right) / \mathrm{CN}_{300} \quad Z=300 \mathrm{~m}
\end{aligned}
$$

This calculation takes into account changes in the $\mathrm{CN}$ concentration with altitude and depends upon our second assumption, i.e. that the concentration of the AP that enter cloud base does not change as a result of cloud processes, 

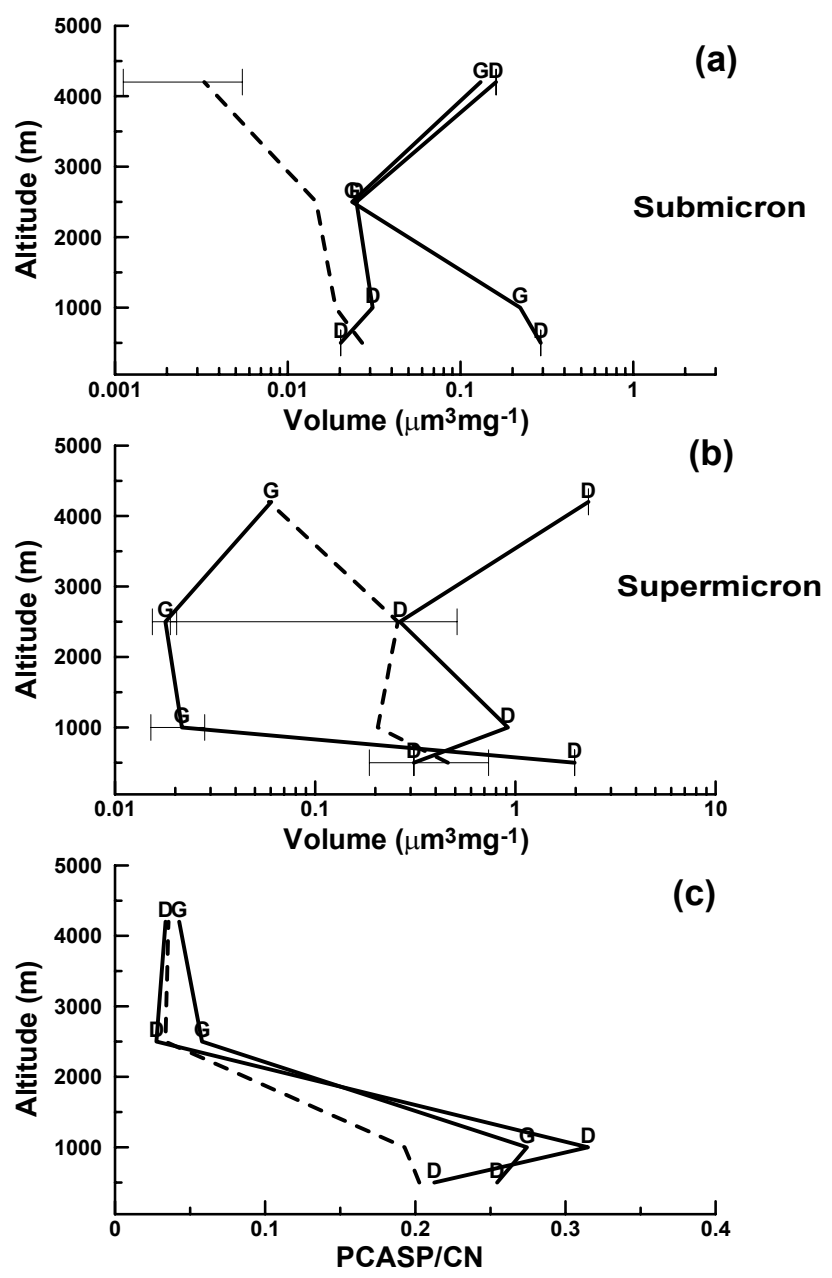

Fig. 5. Vertical profiles of (a) submicron and (b) supermicron volume concentrations comparing near-cloud regions (solid) with the environmental averages (dashed). The letters designate whether a near-cloud region was on the growing $(G)$ or dissipating $(D)$ side of the cloud. The standard deviation around the averages is shown with the horizontal bars. The vertical profiles shown in (c) are the ratios of PCASP to $\mathrm{CN}$ number concentration.

but does allow for the possibility that there are elevated layers of particles, in the far-from-cloud environment, that could mix with detrained air. In addition we are assuming that the concentrations of $\mathrm{CN}$ found at $300 \mathrm{~m}$ far-from-cloud are the same as enter at cloud base. Clearly droplet coalescence and inertial scavenging will remove some fraction of the total $\mathrm{CN}$; however, the $\mathrm{CN}$ concentrations are dominated by particles $<0.1 \mu \mathrm{m}$ that are not efficiently scavenged by cloud droplets. In addition, coalescence primarily removes the supermicron particles and only a small fraction of the submicron population. Hence, we are utilizing the total number concentration as a quasi-conservative tracer to estimate the mixing fractions. A decrease in the concentration of environmental $\mathrm{CN}$ with altitude, will result in a negative value for the factor $f$ as a result of the denominator in Eq. (2). Figure 4 shows the vertical profiles of the CN and PCASP concentrations for the five flights that were evaluated.

Equation (1) was evaluated for each of the near-cloud regions, separating the volume concentrations into their submicron and super micron components. As a result of this analysis, three types of volume changes have been identified that we associate with cloud processed AP: 1) enhanced volumes of submicron AP, 2) enhanced volumes of supermicron AP and 3) removal of supermicron AP. Figure $5 a$ and $b$ illustrate these three types. For example, in the vertical profile shown in Fig. 5a, the measured submicron volume concentrations at all levels exceed the $300 \mathrm{~m}$ concentration far-from-cloud, i.e. submicron volume enhancement. In Fig. 5b, some of the near-cloud regions have enhanced supermicron volume with respect to the $300 \mathrm{~m}$ volume, but several of the near-cloud volumes are smaller than even the far cloud environment. This latter characteristic is what we are identifying as supermicron particle removal.

The volume of AP increases primarily through four mechanisms: 1) mixing with environmental air whose particle volume is higher than at cloud base, 2) growth of particles by uptake of gases by water droplets and conversion to particle mass, 3) droplet coalescence, or 4) scavenging of interstitial AP by cloud droplets. Given that the far-from-cloud AP volume, shown in Fig. 5a, is less than cloud base, the enhanced volume in this case is not a result of mixing with the environment. There are other cases, however, where the volume concentration of particles is larger at higher altitudes, and would contribute to enhanced volume when mixed with detrained air. The vertical profiles of $\mathrm{CN}$ for flights 7 and 9 (Fig. 4) show this characteristic.

The submicron particle volume is derived from the measurements with the PCASP whose minimum size threshold is $0.1 \mu \mathrm{m}$. Enhancement of AP volume will be observed when particle with sizes less than $0.1 \mu \mathrm{m}$ grow into the range of the PCASP. This type of volume enhancement is evaluated by calculating the ratio of PCASP to $\mathrm{CN}$ concentration. When this ratio increases with respect to the reference value, it indicates that the number of particles larger than $0.1 \mu \mathrm{m}$ increased more rapidly than the total number concentration. This indicates that particles have increased in size, presumably due to cloud processing, since mixing should change by the same amount the relative concentration of $\mathrm{CN}$ and PCASP. Figure $5 \mathrm{c}$ shows a vertical profile of this ratio for one of the cases studied. The increase in the ratio from $300 \mathrm{~m}$ to $1000 \mathrm{~m}$ suggests that AP volumes are increasing as a result of particles that grow into the detectable size range of the PCASP.

The AP volume will increase when precursor gases like $\mathrm{SO}_{2}$ dissolve into water droplets, followed by aqueous phase chemical reactions that convert the gas to liquid or solid phase that adds to the mass of the existing droplet nuclei (Hegg et al., 1982, 1983; Flossmann et al., 1987; Flossmann and Pruppaccher, 1988; O'Dowd et al., 2000; Alfonso and Raga, 2002). 
Coalescence combines the masses of nuclei in the two droplets (Flossmann et al., 1987; Alfonso and Raga, 2002). The increase in volume at sizes larger than $1 \mu \mathrm{m}$ shown in the vertical profile of the dissipating region near cloud (Fig. 5b) can be a result of this mechanism; however, uptake of $\mathrm{SO}_{2}$, as well as the scavenging of unactivated AP by cloud droplets, will also enhance the volume of supermicron particles (Hobbs, 1993)

Precipitation is a cloud processing mechanism that removes AP from the atmosphere (Flossmann et al., 1985). Supermicron AP are the first to be activated as cloud droplet and subsequently the most likely to grow to precipitable sizes. The vertical profile of supermicron particle volumes on the growing side of the cloud, shown in Fig. 5b, shows that nearcloud volume is substantially less than the far-from-cloud volumes. This is evidence that precipitation has removed some of the supermicron particles by the time these nearcloud regions were measured.

\section{Results}

Cloud systems were selected for analysis based on the size of the clouds, their continuity and an inspection of the visual records made with the forward and side-looking video cameras on the aircraft. The acceptance criterion required that cloud lines were isolated from adjoining clouds by no less than $10 \mathrm{~km}$ so that far-cloud samples would represent "ambient" AP. The flights were also classified by AP origin, i.e. continental or maritime, based on the maximum values of $\mathrm{CN}$ and PCASP concentrations over the altitude range from 30 to $4200 \mathrm{~m}$, the same range used for the cloud studies. Figure 4 shows the vertical profiles of average, cloud-free $\mathrm{CN}$ and PCASP concentrations for the five research days of this study, where $\mathrm{CN}$ concentrations larger than $500 \mathrm{~cm}^{-3}$ are indicative of air masses from the continent. On the days of Flights 7, 9 and 17 the maximum, environmental $\mathrm{CN}$ concentrations were much higher than the other two flights selected for the analysis (Table 2). The fluctuations of $\mathrm{CN}$ and PCASP concentrations, indicated by the standard deviations about the averages (horizontal bars), were larger on the days when air masses were of continental origin. A back trajectory analysis, using the NOAA HYSPLIT model (http://www.arl.noaa.gov/ready/hysplit4.html), indicated that the anthropogenic particles were from southern Mexico or northern Central America on the days of continental air masses. Flights 12 and 13 were on days with maritime AP background when winds were from the southwest. Table 2 summarizes the time of day, location and origin of the AP.

Each of the near-cloud particle populations were categorized into one or more of the three cloud processing types that were discussed in Sect. 2.4. Multiple classifications are possible, for example sub and supermicron particle volumes can be enhanced within the same region. Thirty two near-

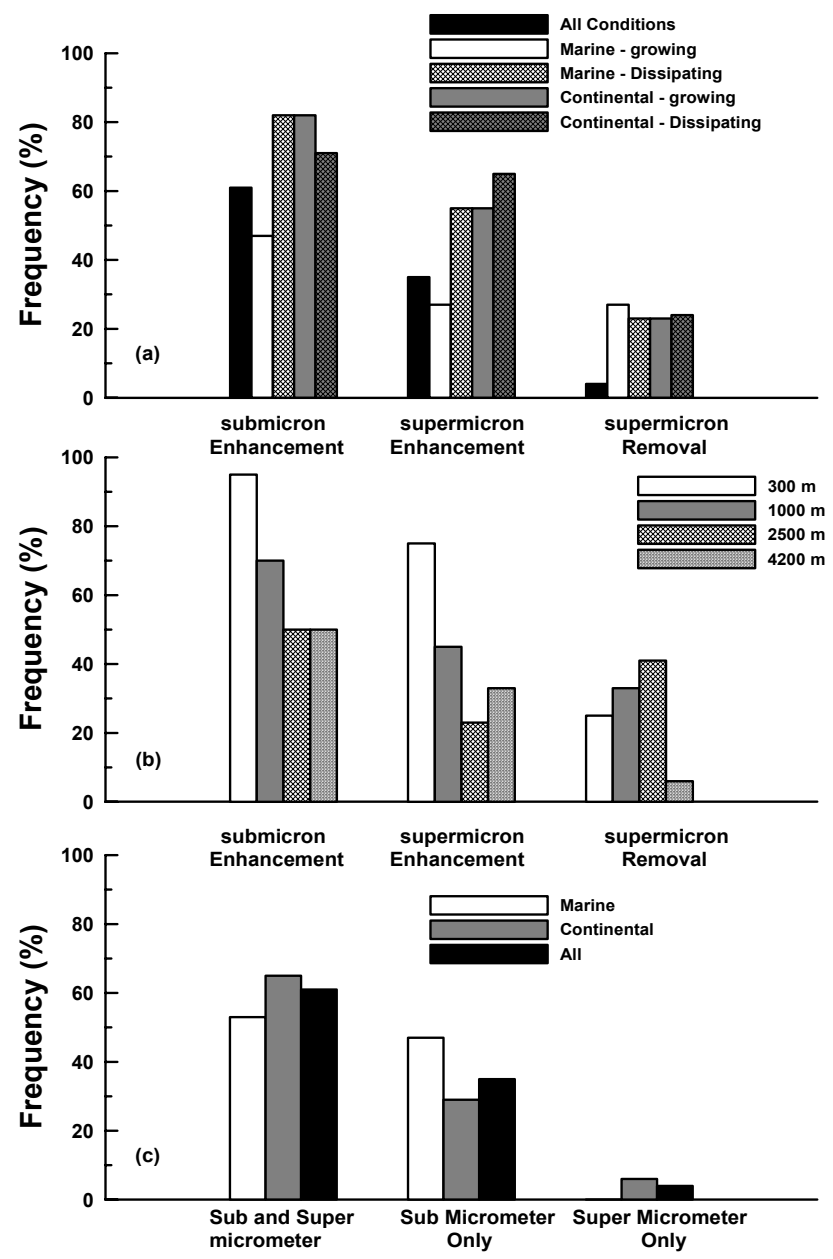

Fig. 6. The frequency of occurrence of different types of cloud processed AP are summarized here stratified by (a) the growing:dissipating side of cloud and particle source, (b) the altitude and (c) type of volume enhancement.

cloud regions were evaluated on clean days and 46 on polluted days. The frequency with which the processing types occurred was evaluated according to altitude, AP origin and near-cloud age or activity, i.e. if the region was on the growing or dissipating side of the cloud. Table 3 summarizes these results.

The final row in Table 3 shows that of the 78 cases analyzed, $68 \%$ and $45 \%$ had enhanced volumes of submicron and submicron particles, respectively, and supermicron particles had been removed in 35\% of the regions. This is shown in Fig. 6a by the solid bar. Also shown in this figure are the frequencies of the three cloud processing types, stratified by air mass origin and further delineated by growth or dissipation. In this figure we see that cases with continental origins had a higher frequency of sub and supermicron volume enhancement than regions with maritime origins. The frequency of supermicron particle removal was insensitive to air mass origin. 
Table 3. Frequency of cloud processed AP types (percentage) $G=$ Growing side of cloud, D = Dissipating side of cloud.

\begin{tabular}{|c|c|c|c|c|c|c|c|c|c|}
\hline \multirow[t]{2}{*}{ Case Type } & \multirow[t]{2}{*}{ Altitude $\mathrm{m}$} & \multicolumn{2}{|c|}{ Number of Cases } & \multicolumn{2}{|c|}{ Submicron Size Increase \% } & \multicolumn{2}{|c|}{ Supermicron Size Increase \% } & \multicolumn{2}{|c|}{ Supermicron Removal \% } \\
\hline & & $\mathrm{G}$ & $\mathrm{D}$ & G & $\mathrm{D}$ & G & $\mathrm{D}$ & $\mathrm{G}$ & $\mathrm{D}$ \\
\hline \multirow{4}{*}{ Continental } & 300 & 5 & 7 & 100 & 100 & 100 & 86 & 0 & 14 \\
\hline & 1000 & 7 & 5 & 86 & 80 & 42 & 60 & 28 & 0 \\
\hline & 2500 & 7 & 5 & 86 & 20 & 42 & 20 & 42 & 60 \\
\hline & 4200 & 3 & 7 & 33 & 57 & 33 & 42 & 0 & 14 \\
\hline All continental & & 22 & 24 & 82 & 67 & 55 & 54 & 23 & 21 \\
\hline \multirow{4}{*}{ Marine } & 300 & 2 & 6 & 100 & 83 & 50 & 50 & 50 & 33 \\
\hline & 1000 & 5 & 3 & 40 & 67 & 40 & 33 & 40 & 67 \\
\hline & 2500 & 5 & 3 & 60 & 33 & 20 & 0 & 20 & 33 \\
\hline & 4200 & 3 & 5 & 0 & 80 & 0 & 40 & 0 & 0 \\
\hline All marine & & 15 & 17 & 47 & 71 & 27 & 35 & 27 & 29 \\
\hline \multirow{4}{*}{ Combined } & 300 & 7 & 13 & 100 & 92 & 86 & 69 & 14 & 23 \\
\hline & 1000 & 12 & 8 & 67 & 75 & 42 & 50 & 33 & 25 \\
\hline & 2500 & 14 & 8 & 64 & 25 & 29 & 13 & 4 & 4 \\
\hline & 4200 & 6 & 12 & 17 & 67 & 17 & 42 & 0 & 1 \\
\hline All altitudes & & 37 & 41 & 68 & 68 & 43 & 46 & 24 & 24 \\
\hline All conditions & & & 8 & & & & & & \\
\hline
\end{tabular}

The volume enhancement frequency, for sub and supermicron particles, was almost twice as high on the dissipating side of maritime clouds than on the growing sides. On the other hand, continental clouds did not show the same sensitivity to the near-cloud age.

The frequency of sub and supermicron volume enhancement decreased with increasing altitude, by almost a factor of two, between $300 \mathrm{~m}$ and $2500 \mathrm{~m}$ (Fig. 6b). The reverse occurred for cloud processing by supermicron particle removal.

The frequency in volume enhancement was further stratified by evaluating how often sub and supermicron enhancement occurred simultaneously, compared with one or the other happening individually. Figure $6 c$ shows that enhancement occurs simultaneously $60 \%$ of the time (solid bar). The enhancement of only submicron volume was $15 \%$ more frequent for regions of maritime origin.

\section{Discussion}

The observations are consistent with results from previous observational (Hegg and Hobbs, 1981, 1982) and theoretical (Flossmann et al., 1985; Flossmann, 1998) studies that showed shifts in the size distribution of boundary layer AP to larger sizes by the combined processes of $\mathrm{SO}_{2}$ uptake and sulfate particle scavenging. In the current study about $60 \%$ of the near-cloud regions had enhanced volumes of submicron sizes and $40 \%$ had experienced enhancement of supermicron volumes.
The enhancement in volume in both sub and super micron particles, in $60 \%$ of the cases (Fig. 6c), is in qualitative agreement with modeling studies (Flossmann et al., 1987; Alfonso and Raga, 2002) that showed that the scavenging of $\mathrm{SO}_{2}$ by small water droplets and subsequent conversion to sulfate increases the mass of the AP cloud nuclei over all sizes. In addition, larger water droplets contain more sulfate as a result of the scavenging of $\mathrm{SO}_{2}$ and the coalescence by smaller droplets into larger ones. The results of Flossmann et al. (1987) also showed that the size distribution of the aerosol particles that remained after the cloud evaporated had shifted to larger sizes than those that entered as cloud base AP. This result is supported by the observations from this study, as shown in the enhancement of sub and supermicron particles.

The composition of the AP was not measured in the EPIC observations, but the enhancement in mass was estimated by converting the volume concentrations to mass mixing ratios with the assumption that the particles are ammonium sulfate. Figures $7 \mathrm{a}-\mathrm{d}$ show frequency diagrams of the residual particle mass concentration derived using Eq. (1), and stratified according to particle size range (sub and super micron) and air mass origin. The mass concentration is expressed as a mixing ratio, in units of microgram of mass per kilogram of air, in order to remove the effect of air density changes with altitude and to facilitate comparisons with previous modeling results. The total residual mass ranged from 0.006$10 \mu \mathrm{g} \mathrm{kg}^{-1}$ with an average of $2.4 \pm 2.4 \mu \mathrm{g} \mathrm{kg}^{-1}$. The average enhancement in submicron mass was $0.5 \pm 0.5 \mu \mathrm{g} \mathrm{kg}^{-1}$ 


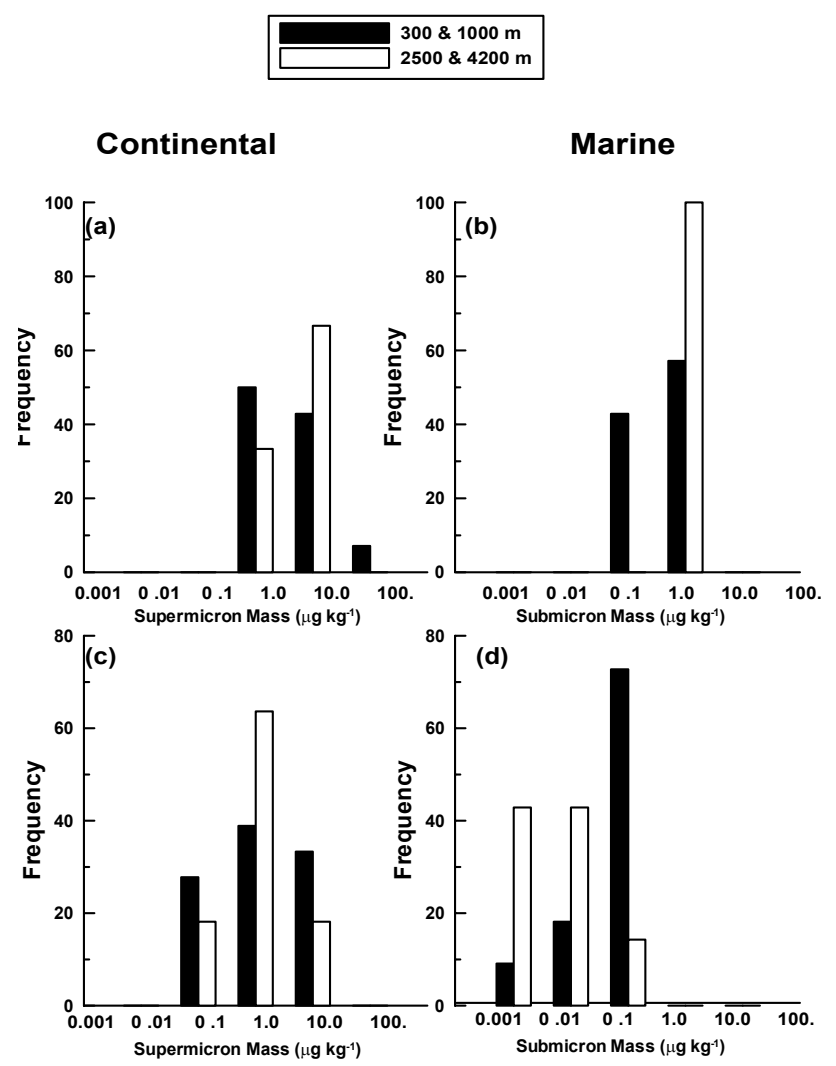

Fig. 7. The frequency of occurrence of differences between nearcloud and cloud base AP mass is shown here stratified by air mass origin, particle size range, and stratified by altitude, $300 \mathrm{~m}$ and $1000 \mathrm{~m}$ levels combined (solid bars) and 2500 and $4200 \mathrm{~m}$ levels, combined (open bars).

and in supermicron mass, $2.4 \pm 2.4 \mu \mathrm{g} \mathrm{kg}^{-1}$. The average total mass enhancements for the continental and maritime cases were $2.5 \pm 2.4$ and $2.2 \pm 2.5 \mu \mathrm{g} \mathrm{kg}^{-1}$, respectively.

The average residual mass in the submicron particles, for the continental and maritime cases, was $0.6 \pm 0.6$ and $0.1 \pm 0.2$, respectively (Fig. $7 c, d$ ). The majority of supermicron residuals had a mass of 10 and $1 \mu \mathrm{g} \mathrm{kg}^{-1}$ for continental and maritime air masses (Fig. 7a, b).

The total estimated enhancement in sulfate mass of 0.02 to $10 \mu \mathrm{g} \mathrm{kg}^{-1}$ is consistent with previous observations and modeling predictions. Measurements of sulfate upwind and downwind of wave clouds over the state of Washington showed enhancements of up to $10 \mu \mathrm{g} \mathrm{kg}^{-1}$ (Hegg and Hobbs, 1981). Estimates were made of enhancements from sulfate measurements of cloud droplets over the Los Angeles Basin and Western Washington State where sulfate in excess of ambient values ranged from $0.15-29 \mu \mathrm{g} \mathrm{kg}^{-1}$. The Flossmann et al. (1987) model predicted increases of sulfate in cloud drops from 0 to $4 \mu \mathrm{g} \mathrm{kg}^{-1}$, depending upon the assumed scavenging rate of AP by cloud droplets, conversion rates of $\mathrm{SO}_{2}$ to sulfate in the droplets, and the amount of time in cloud.
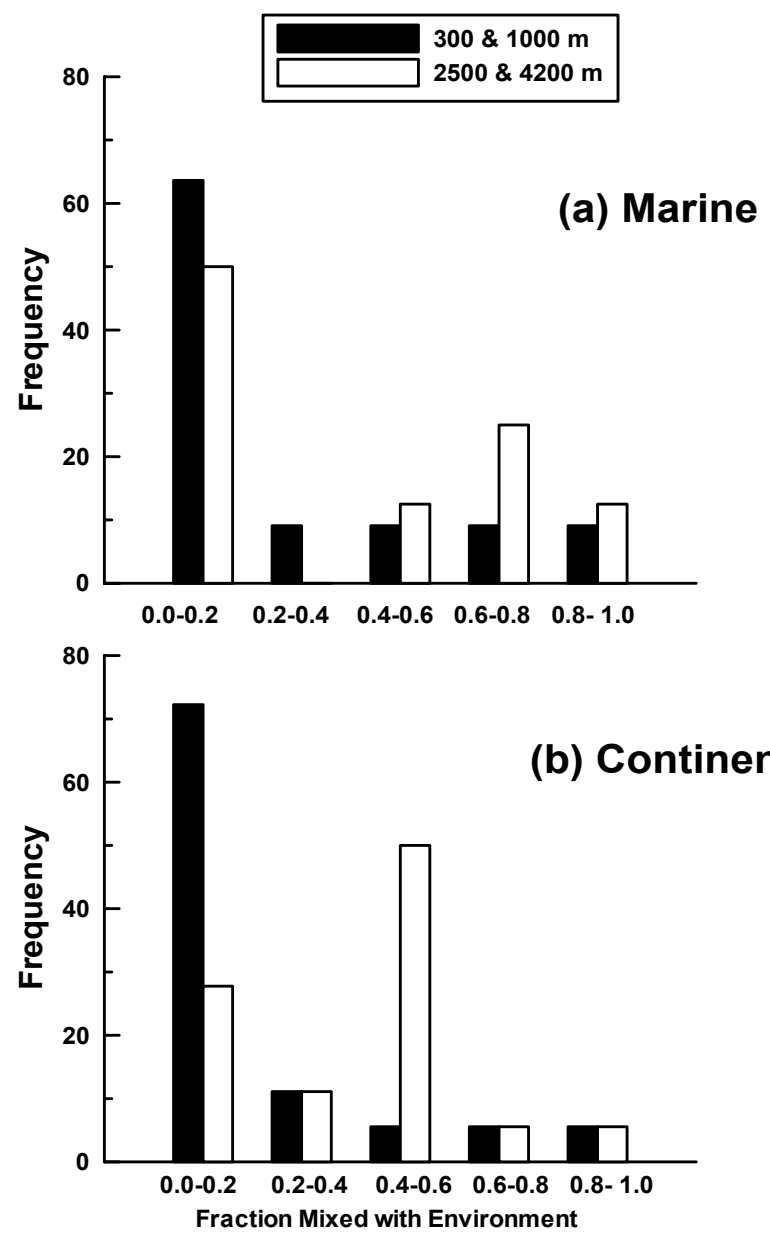

Fig. 8. The fraction of far-cloud air in the near-cloud regions was calculated from Eq. (2) and shown here as the frequency of nearcloud regions with different amounts of mixing. A value of 0 signifies that a near-cloud region had mixed with almost no far-cloud air. The mixing fraction frequency is stratified by altitude, $300 \mathrm{~m}$ and $1000 \mathrm{~m}$ levels combined (solid bars) and 2500 and $4200 \mathrm{~m} \mathrm{lev-}$ els, combined (open bars), and by air mass origin, maritime (a) and continental (b).

The majority of near-cloud regions at $1000 \mathrm{~m}$ and cloud base had mixed very little with far-cloud air. As shown in Fig. 8 more than $60 \%$ of the maritime and continental regions had mixing fractions less than 0.2 , as calculated from the $\mathrm{CN}$ measurements in Eq. (2). At the 2500 and $4200 \mathrm{~m}$ levels, a larger frequency of near-cloud regions was mixed with $50 \%$ or more of far-cloud air.

As discussed previously, the near-cloud environments were stratified by their growing or dissipating state. This classification, albeit qualitative, is based on the conceptual idea that convective clouds have a growing, inflow side with vigorous updrafts and new droplet activation and a dissipating, outflow side with downdrafts, precipitation and detrainment of cloud air mixed with far-cloud air. Our results indicate that only in the cases of marine origin did it matter if 
the near-cloud region was growing or dissipating. As shown in Fig. 6a, the dissipating side of marine clouds was almost twice as likely to have enhanced sub and supermicron volume enhancement as the growing side. This result is consistent with our conceptual idea that there should be less detrainment on the growing side of clouds than on their dissipating side. In the continental cases, however, there was little difference between growing and dissipating sides. The reason for this difference between clouds of continental and maritime origin remains an open question at this time. One possible explanation, however, is that because of the difference between the maritime and continental clouds in terms of variations in the growing and dissipating sides, for the case of continental clouds, the aerosol modification must have occurred in the early stages of the droplet lifetime, whereas in the former the modification must be continuing throughout the clouds dynamical cycle.

\section{Summary and conclusions}

In situ measurements of the size distributions of particles in regions around convective clouds within the Mexican ITCZ were analyzed to evaluate the relative magnitude of changes in the physical and chemical properties of aerosol particles cause by aqueous phase chemistry, particle scavenging, coalescence and removal by precipitation. The growth in volume of particles, presumably by $\mathrm{SO}_{2}$ and sulfate particle scavenging, was the process most frequently identified by the measurements. The second most frequent was enhancement of the volume of supermicron particles through the coalescence of droplets. The average increase in mass, estimated from comparisons of cloud base and near-cloud size distributions, is consistent with previously published theoretical predictions for marine convective clouds.

Particles whose mass has increased as a result of their passage through clouds will interact differently with the environment than those unchanged. Redistribution and growth to larger sizes produces particles that activate at lower supersaturations and grow more quickly to precipitable sizes (Flossmann, 1998). Larger particles scatter light more efficiently and will increase the optical extinction in near-cloud regions. Both of these effects have important climatological ramifications and are the focus the Part II paper that is presently in preparation.

Acknowledgements. The authors are grateful to D. Raymond for enabling UNAM's participation in EPIC2001. We also thank the technical staff and flight crew of the NCAR C-130. Two anonymous reviewers provided valuable comments and suggestions that enhanced the quality of the manuscript. The study was funded through CONACYT grant \# 33319 and UNAM-DGAPA.

Edited by: K. Carslaw

\section{References}

Alfonso, L. and Raga, G. B.: Estimating the impact of natural and anthropogenic emissions on cloud chemistry Part I. Sulfur cycle, Atmos. Res., 62, 33-55, 2002.

Baumgardner, D., Strapp, J. W., and Dye, J. E.: Evaluation of the forward scattering spectrometer probe: Part II. Corrections for coincidence and dead-time losses, J. Atmos. Oceanic Tech., 2, 626-632, 1985.

Baumgardner, D. and Spowart, M.: Evaluation of the forward scattering spectrometer probe: Part III. Time response and laser inhomogeneity limitations, J. Atmos. Oceanic Tech., 7, 666-672, 1990.

Baumgardner, D., Huebert, B., and Wilson, C.: Meeting Review: Airborne aerosol inlet workshop, NCAR Tech. Note TN362+1A, 288 pp., 1991.

Baumgardner, D., Dye, J. E., Knollenberg, R. G., and Gandrud, B. W.: Interpretation of measurements made by the FSSP-300X during the Airborne Arctic Stratospheric Expedition, J. Geophys. Res., 97, 8035-8046, 1992.

Baumgardner, D. and Clarke, A.: Changes in aerosol properties with relative humidity in the remote southern hemisphere marine boundary layer, J. Geophys. Res., 103, 16 525-16534, 1998.

DeFelice, T. P. and Cheng, R. J.: On the phenomenon of nuclei enhancement during the evaporative stage of a cloud, Atmos. Res., 47-48, 15-40, 1998.

Flossmann, A. I., Hall, W. H., and Pruppacher, H. R.: A theoretical study of the wet removal of atmospheric pollutants. Part I: The redistribution of aerosol particles captured through nucleation and impaction scavenging by growing cloud drops, J. Atmos. Sci., 42, 583-606, 1985.

Flossmann, A. I., Pruppacher, H. R., and Topalian, J. H.: A theoretical study of the wet removal of atmospheric pollutants. Part II: The uptake and redistribution of $\mathrm{NH}_{42} \mathrm{SO}_{4}$ particles and $\mathrm{SO}_{2}$ gas simultaneously scavenged by growing cloud drops, J. Atmos. Sci., 44, 2912-2923, 1987.

Flossmann, A. I. and Pruppacher, H. R.: A theoretical study of the wet removal of atmospheric pollutants. Part III: The uptake, redistribution, and deposition of $\mathrm{NH}_{42} \mathrm{SO}_{4}$ particles by a convective cloud using a two-dimensional cloud dynamics model, J. Atmos. Sci., 45, 1857-1871, 1988.

Flossmann, A. I.: Interaction of Aerosol Particles and Clouds, J. Atmos. Sci., 55, 879-887, 1998.

Hegg, D. A. and Hobbs, P. V.: Cloud water chemistry and the production of sulfate in clouds, Atmos. Environ., 15, 1597-1604, 1981.

Hegg, D. A. and Hobbs, P. V.: Measurements of sulfate production in atmospheric clouds, Atmos. Environ., 16, 2663-2668, 1982.

Kaneyasu, N., Hobbs, P. V., Isjizaka, Y., and Quian, G. W.: Aerosol properties around marine tropical cumulus clouds, J. Geophys. Res., 106, 14 435-14 445, 2001.

Kim, Y. J. and Boatman, J. F.: The effects that the optical properties of particles have on atmospheric aerosol measurements with optical particle spectrometers, J. Aerosol Sci., 21, Supp. 1, S551S554, 1990.

O' Dowd, C. D., Lowe, J. A., and Smith, M. H.: The effect of clouds on aerosol growth in the rural atmosphere, Atmos. Res., 54, 201-221, 2000.

Raga, G. B. and Jonas, P. R.: Microphysical and radiative properties of small cumulus clouds over the sea, Quart. J. Royal Meteor. 
Soc., 119, 1399-1417, 1993a.

Raga, G. B. and Jonas, P. R.: On the link between cloud-top radiative properties and sub-cloud aerosol concentrations, Quart. J. Royal Meteor. Soc., 119, 1419-1425, 1993b.

Raymond, D. J., Esbensen, S. K., Paulson, C., Gregg, M., Bretherton, C. S., Petersen, W. A., Cifelli, R., Shay, L. K., Ohlmann, C., and Zuidema, P.: EPIC2001 and the Coupled OceanAtmosphere System of the Tropical East Pacific, Bulletin of the American Meteorological Society, 85, 9, 1341-1354, 2004.

Saxena, V. K., Burford, J. N., and Kassner Jr., J. L.: Operation of a Thermal Diffusion Chamber for Measurements on Cloud Condensation Nuclei, J. Atmos. Sci., 27, 73-80, 1970.
Strapp, J. W., Leaitch, W. R., and Liu, P. S. K.: Hydrated and dried aerosol-size distribution measurements from the particle measuring systems FSSP-300 probe and the deiced PSASP-100X probe, J. Atmos. Ocean. Tech., 9, 548-555, 1992.

Tang, I. N.: Deliquescence Properties and Particle size change of Hygroscopic Aerosols, in: Generation of Aerosols, Science Publishers, Chapter 7, 153-167, 1980.

Twohy, C.: Airborne condensation nucleus counter user's guide, NCAR TEchnical Note, NCAR/TN-356+EDD, 21 pp., 1991.

Twomey, S.: Pollution and the planetary albedo, Atmos. Environ., 8, 1251-1256, 1974.

Twomey, S.: Aerosols Clouds and Radiation, Atmos. Environ., 25A, 2435-2442, 1991. 